\title{
Can Visual Discomfort Influence on Muscle Pain and Muscle Load for Visual Display Unit (VDU) Workers?
}

\author{
A. Aarås, G. Horgen, and M. Helland \\ Department of Optometry and Visual Science, \\ Buskerud University College, P.O. Box 251, \\ N-3603, Kongsberg, Norway \\ Arne.aaras@hibu.no
}

\begin{abstract}
In three different prospective epidemiological studies, correlation between visual discomfort and average pain intensity in the neck and shoulder, were $0.30<\mathrm{r}<0.72$ for VDU workers. In the first study, correlation between visual discomfort and pain in the neck and shoulder was $0.30<\mathrm{r}<0.40$. In the second study, visual discomfort was related to neck pain, $(r=0.40, p=0.003)$. In the third study, visual discomfort correlated to neck pain $(\mathrm{r}=0.69, \mathrm{p}=0.000)$ and shoulder pain $(\mathrm{r}=0.72, \mathrm{p}=0.000)$. In order to study more in detail the correlation between visual stress and muscle load, a laboratory study was carried out. Visual stress was induced by the size of characters on the screen (8 points and 12 points Times New Roman) and the luminance levels in the surroundings of the screen (between 1500 and $2300 \mathrm{~cd} / \mathrm{m}^{2}$ ) versus (between70 and $100 \mathrm{~cd} / \mathrm{m}^{2}$ ). The results showed that the smallest characters 8 points and the highest luminance levels had no significant influence on the muscle load in neck and shoulder regions. However, the productivity was significant lower when using the 8 points characters compared with 12 points. There was also a tendency to an increase in the number of errors made.
\end{abstract}

Keywords: VDU workplaces. Lighting conditions, Visual conditions, Visual discomfort, Musculoskeletal illness, Eye blinking.

\section{Introduction}

Visual discomfort has a high prevalence for VDU workers [1]. Eye discomfort is related to VDU work according to Bergqvist and Knave. They found that symptoms of gritty feeling or redness of the eye as well as sensitivity to light were associated with VDU work [2]. Bergqvist et al. documented also a positive dose-response association between eye discomfort and VDU use [3]. Furthermore, Sjøgren and Elfstrøm found that the frequency of eye discomfort was related to working time at the VDU [4]. Both lighting conditions and optometric corrections are documented to be important to reduce visual discomfort [5]. Glare has significant correlations to eye focusing problems and tired eyes [6]. In a laboratory study by Sheedy and Bailey, glare from a luminarie in the upper visual field was examined. Subjective rating of light discomfort was strongly related to the luminance level of the glare source. Further, the glare magnitude was significantly related to asthenopic symptoms 
$(\mathrm{p}=0.004)$ and musculoskeletal symptoms $(\mathrm{p}=0.017)$ [7].Horgen et al. has shown that optometric corrections reduced visual discomfort and musculoskeletal pain in VDU workers [8]. More details regarding VDU work and health consequences for such work are given by Aarås et al. [8]. Punnet and Bergqvist reported very frequently pain in the musculoskeletal system for VDU workers [9]. Static muscle load, high frequency of repetitive movements and high force requirements of these movements seem to be predictors for onset of musculoskeletal discomfort [10]. Duration of repetitive movements of the upper arm was found to be associated with neck and shoulder symptoms [10].Up till now, few studies have examined relationship between visual discomfort and musculoskeletal pain.

\section{Epidemiological Studies}

The aims of these studies were to investigate the correlation between visual discomfort and pain in the upper part of the body. Longitudinal epidemiological studies were performed to evaluate the aims $[5,11]$.

\subsection{The First Study}

This was a prospective epidemiological study where VDU workers were followed for a period of six years. Visual discomfort showed a relationship with pain intensity in the neck and shoulder $(0.30<\mathrm{r}<0.40)$ [12]. The level of discomfort/pain was assessed on a Visual Analogue Scale (VAS). Visual discomfort was 29.9 (21.7- 38.09) and shoulder pain 23 (15.3-30.7) as group mean with $95 \%$ Confidence Interval (CI). Zero was no pain 100 indicated extreme or unbearable pain. However, such studies have a lot of confounding factors such as organizational and psychosocial factors. For all psychosocial factors, there was no statistical intervention effect or time effect and no interactions between time and intervention were found.

\subsection{The Second Prospective Field Study}

This study was a multidisciplinary multinational ergonomic study MEPS (musculoskeletal-eyestrain - psychosocial - stress). The objective of the study was to examine the effects of various kinds of ergonomic interventions including corrective lenses on a combination of musculoskeletal, postural, and psychosocial outcomes among VDU workers. In this study, visual discomfort was related to neck pain, $\mathrm{r}=0.40, \mathrm{p}=0.003$; regression coefficient 0.37 with $\mathrm{CI}$ of $0.18-0.57$. Neck pain was also related to burning and itching of the eye $(\mathrm{p}=0.004)$. Headache was related to visual discomfort, $(r=0.34, p=0.01)$ [13].

\subsection{The Third Epidemiological Study}

This is the same study as described in 2.1, where the follow up period covers from 6 to 13 years. The results showed a significant correlation between visual discomfort and neck pain $(\mathrm{r}=0.64, \mathrm{p}=0.000)$ as well as shoulder pain $(\mathrm{r}=0.56, \mathrm{p}=0.001)$. For the forearm this correlation was weaker, but still significant $(r=0.35, p=0.04)$. In a 
multivariable regression model when lighting and glare were excluded, visual discomfort explained $53 \%$ of the variance of the neck and shoulder pain [14].

\section{Laboratory Study}

The aims of the study was to evaluate how the luminance levels of the surroundings of VDU and the size of the characters on the screen effect the muscle load, the accommodation and the fixation pattern during VDU work [15].

\subsection{The Design and Methods of the Study}

The design and the methods of the study are described by Horgen et al. [15].The experiment was conducted at an optimised VDU workplace. The table was adjustable and constructed to give support for the forearms on the tabletop [16]. The illumination

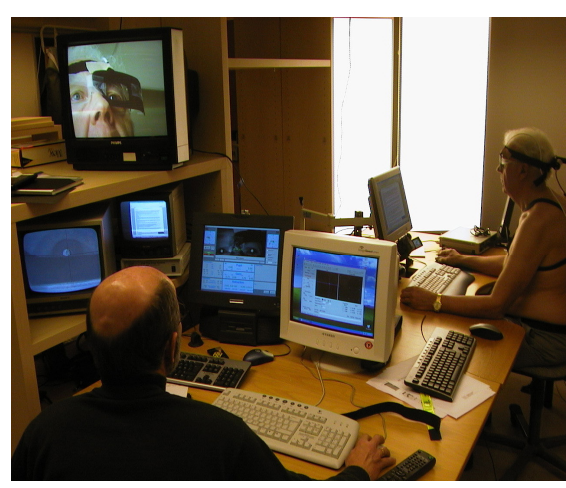

Fig. 1. The Workplace, with glare source level was approximately $500 \mathrm{~lx}$ on the work table. The line of sight to the midpoint of the screen was approximately $15^{\circ}$ below horizontal. A constant visual distance from the eye to the midpoint of the screen was set to approximately $60 \mathrm{~cm}[17,18]$. The "glare" luminaries had each two $40 \mathrm{~W}$ fluorescent tubes, with a diffusing screen of opal acrylic sheet $1.25 \mathrm{~m} \times 0.57 \mathrm{~m}$, giving a luminance between $1500-2300 \mathrm{~cd} / \mathrm{m}^{2}$ (measured across the screen) [15]. These two "glare" luminaries were mounted vertically on the right side of the VDU, at approximately $45^{\circ}$ horizontal angle from the sightline to the centre of the screen, simulating windows as they very often appear in a normal work station set up. The work task was interactive work on a 15 inch LCD screen. The test set up is shown in Fig. 1.

To neutralize the influence of the test sequence, a 3 × 3 orthogonal Latin square design trial was used [19]. The lowest luminance level of the surroundings of the screen, (between 70 and $100 \mathrm{~cd} / \mathrm{m}^{2}$ ), and the normal size of the characters on the screen, (12 points New Roman), were defined as baseline. This baseline was recorded for each participant at the start and the end of the trial. The mean of these two measurements was used as a baseline in the statistical analysis [1]. The smallest text size was 8 points Times New Roman. The combination of high luminance/normal character size, high luminance/small character size and low luminance/small character size was tested according to the orthogonal Latin square design.

The postural load on the neck and shoulder muscles was quantified by electromyography (EMG) using the Physiometer. Surface electrodes were used [20]. The load in $\mathrm{m}$. trapezius (descending part) and $\mathrm{m}$. Infraspinatus was used as indicators 
of load on the neck and shoulder areas. To perform continuous measurement of postural angels, three dual axis inclinometers were used. Angles were measured relative to the vertical by these inclinometers attached to the upper arm, head and back. The angle measurements were mainly used to control the work posture during the VDU work. The EMG and the postural angle methods are described and the methodological limitations discussed [20, 21, 22, 23, 24, 25].

There were five test sessions. Each session lasted 10 minutes of active recording, with a period of rest in between. The reason for 10 minutes active recording for each session is the recommendations by Mathiassen [26], who observed marginal information beyond approximately 10 minutes sampling of EMG of stereotyped work. The rest period was about 5 minutes. 16 subjects were needed in order to detect a difference in muscle load between 0.5 to $1 \%$ Maximum Voluntary Contraction (MVC) at a power level of $80 \%$.

The measurements of eye-tracking and accommodation are described by Horgen et al [15].

\subsection{Results}

The size of the characters and the glare condition had small influence on the muscle load.

M. trapezius activities did not show significant differences when comparing the mean of the two baseline measurements with muscle activities when working with small characters and glare. This was true both for static $(p=0.21)$ and median values $(p=0.07)$ [14].This was opposite what to be expected. For the median muscle load, there was significant higher activity at baseline than when working with small characters with glare $(p=0.008)$ and small characters without glare $(p=0.015)$. The maximal difference in static $m$. trapezius activity within subjects between the baseline and the measurements when the subjects were glared and bolded small characters was $1.8 \%$ MVC.

M. infraspinatus was in most cases relatively heavy loaded. There were no significant differences when comparing the static value of the baseline measurement, working with small characters with glare $(\mathrm{p}=0.11)$ and small characters without glare $(\mathrm{p}=0.14)$. However, when similar comparison for median muscle load were done, there were significant higher activity at baseline then when working with small characters with glare $(\mathrm{p}=0.008)$ and small characters without glare $(\mathrm{p}=0.015)$. The maximal difference for static $m$. infraspinatus activity within subjects between the baseline measurements and the test of the glare and smaller characters was maximal $3.5 \%$ MVC.

Erector spina lumbar part, at L3 level did not show significant differences between the baseline and the three test situations. This was true for both static and median values $(0.13<\mathrm{p}<0.96)$. The maximal induced stress situation within subjects was $2.75 \%$ MVC. Gaze tracking showed that the fixation time within the whole computer screen area was almost $100 \%$ of the total testing time [15].

A small transient myopic shift was observed in spite of the rather mature test subjects. 


\section{Conclusion and Recommendations}

Three different prospective epidemiological studies have shown that there is a clear indication of a relationship between visual discomfort and pain in the neck and shoulder. In a laboratory study visual stress had small influence on the muscle load.

Working with small characters and glare did not impose or increased static muscle load for Trapezius, Infraspinatus and Erector spina. M. infraspinatus was relatively heavy loaded during this type of computer work due to high precision-dependence during tracking work. Productivity, in terms of less amount of text processed was significantly reduced when working with 8 points characters. In addition there was a tendency an increased number of errors when working with glare. A reasonable explanation of the differences in the results between the epidemiological and the laboratory studies may be that in the laboratory study the visual stress in terms of small character and glare reduced the productivity. Reduced productivity may reduce the static muscle load and pain. For presbyoptic VDU workers, the character size should be more than 8 points letters. According to a study by Helland et al. [27], glare had a significant correlation to visual discomfort, $\mathrm{r}_{\mathrm{s}}=0.35, \mathrm{p}=0.040$. They showed also that visual discomfort explained $53 \%$ of the variance of the neck and shoulder pain in VDU workers.

\section{References}

1. Horgen, G., Aarås, A.: Visual discomfort among vdu-users wearing single vision lenses compared to vdu-progressive lenses. Paper presented at the Human Computer International 2003, Crete (2003)

2. Bergqvist, U., Knave, B.: Eye discomfort and work with visual display terminals. Scandinavian Journal of Work Environment and Health 20, 27-33 (1994)

3. Bergqvist, U., Knave, B., Voss, M., Wibom, R.: A longitudinal study of VDT work and health. International Journal of Human-Computer Interaction 4, 197-219 (1992)

4. Sjøgren, S., Elfstrøm, A.: Eye discomfort among 1000 VDT-workers. In: Proceedings of the 2nr International Conference on Work With Display Units, Montreal, Canada, 35. Montreal Quebec, Canada: Institut de Recherche en Sante et an Scurite du Travail (1989)

5. Aarås, A., Horgen, G., Bjørset, H.-H., Ro, O.: Musculoskeletal, visual and psychosocial stress before and after multidisciplinary ergonomic interventions. In: Applied Ergonomics, 29th edn., pp. 335-354. Elsevier Science Ltd, Great Britain (1998)

6. Hedge, A., Williams, R.S.J., Franklin, D.B.: Effects of lensed-indirect and parabolic lighting on the satisfaction, visual health, and productivity of office workers. Ergonomics 38(2), 260-280 (1995)

7. Sheedy, J.E., Bailey: Symptoms and reading performance with performance with peripheral glare sources. Paper presented at the Work With Display Units 94, University of Milan (1995)

8. Aarås, A., Horgen, G., Ro, O.: Work with the visual display unit: Health consequences. International Journal of Human-Computer Interaction 12(1), 107 (2000)

9. Punnet, L., Bergquist, U.: Visual display unit work and upper extremity musculoskeletal disorders. A review of epidemiological findings (1997) (No.ISBN: 91-7045-436-1) 
10. Mikkelsen, S., Andersen, J.H., Bonde, J.P., Fallentin, N., Group, a.t. P. H. S.: A longitudinal study on repetition, force and posture and the development of neck, elbow and wrist disorders. Paper presented at the Fourth International Scientific Conference on Prevention of Work-Related Musculoskeletal Disorders, De Meevaart- AmsterdamNetherlands (2001)

11. Aarås, A., Horgen, G., Helland, M.: Do Visual Discomfort influence on Muscle pain for Visual Display Unit (VDU) Workers? In: Proceedings from Nordic Ergonomics Society 37th Annual Conference 2005, pp. 104-105 (2005)

12. Aarås, A., Horgen, G., Bjørset, H.-H., Ro, O., Walsøe, H.: Musculoskeletal, visual and psychosocial stress in VDU operators before and after multidisciplinary ergonomic interventions. Applied Ergonomics 32, 559-571 (2001)

13. Aarås, A., Horgen, G., Ro, O., Mathiasen, G., Bjørset, H.-H., Larsen, S., And Thorsen, M.: The effect of an Ergonomic Intervention on Musculoskeletal, Psychosocial and Visual Strain of VDT Data Entry Work: The Norwegian Part of the International Study. International Journal of Occupational Safety and Ergonomics (JOSE) 11(1), 25-47 (2005)

14. Helland, M., Horgen, G., Kvikstad, T.M., Garthus, T., Bruenech, J.R., Aarås, A.: Musculoskeletal, visual and psychosocial stress in VDU operators before and after multidisciplinary ergonomic interventions. A 13 years prospective study. Part III. Submitted for publication (2006)

15. Horgen, G., Helland, M., Kvikstad, T.M., Aarås, A., Bruenech, J.R.: Do luminance Levels of the Surroundings of Visual Display Units (VDU) and the Size of the Characters on the Screen effect the Accommodation, the Fixation Pattern and the Muscle Load during VDU Work. HCI International Conference, 2005. Las Vegas, Nevada USA (July 22-27, 2005)

16. Aarås, A., Fosstervold, K.I., Ro, O., Larsen, S.: Postrual load during vdu work: A comparison between different work postures. Ergonomics 40(11), 1255-1269 (1997)

17. Jaschinski, W., Heyer, H., H, K.: Preferred position of visual displays relative to the eyes: A field study of visual stain and individual differences. Ergonomics 41(7), 1034-1049 (1998)

18. Saito, S., Taptagaporn, S., Saito, S., Sotoyama, M., Suzuki, T.: Application of the Ophthalmological Aspects of Ocular Position to VDT Workstation Design. In: Luczak, I., Cakir, A.E., Cakir, G.: Work With Display Units. WWDU'92. Technische Universität Berlin Institut für Arbeidswissenschaft, B. 14 (1992)

19. Jones, B., Kenword, M.G.: Design and Analysis of Cross-Over Trials. Capman \& Hall, London (1989)

20. Aarås, A., Veierød, M.B., Ørtengren, R., And Ro, O.: Reproducibility and stability of normalized EMG measurements on musculus trapezius. Ergonomics 39(2), 171-185 (1996)

21. Jonsson, B.: Measurement and evaluation of muscular strain in the shoulder during constrained work. Journal of human Ergol. 11, 73-82 (1982)

22. Aarås, A., Westgaard, R.H., Stranden, E.: Postural angles as an indicator of postural load and muscular injury in occupational work situations. Ergonomics 31(6), 915-933 (1988)

23. Veiersted, K.B., Westgaard, R.H., Andersen, P.: Electromyographic evaluation of muscular work pattern as a predictor of trapezius myalgia. Scan. J. Work Environ. Health. 19, 284-290 (1993)

24. Horgen, G., Aarås, A., Kaiser, H., Thoresen, M.: Do specially designed VDU lenses create increased postural load compared with single-vision lenses during VDU work? Optometry and Vision science 79, 112-120 (2002) 
25. Hagen, K.B., Sørhagen, O., Harms-Ringdahl, K.: Influence of weight and frequency on thigh and lower-trunk motion during repetetive lifting employing stoop and squat techniques. In: Hagen, K.B. (ed.) Physical work load and percieved exertion during forest work and experimental repetetive lifting - thesis, Karolinska Institutet - Stokholm, Stokholm (1994)

26. Mathiassen, S.E., Burdorf, A., van der Beek, A.J.: Statistical power and measurement allocation in ergonomic intervention studies assessing upper m.Trapezius emg amplitude. A case study of assembly work. Journal Electromyography Kinesiology 12, 45-57 (2002)

27. Helland, M., Horgen, G., Kvikstad, T.M., Garthus, T., Bruenech, J.R., Aarås, A.: Musculoskeletal, visual and psychosocial stress in VDU operators before and after multidisciplinary ergonomic interventions. A 13 years prospective study. Part III. Submitted Applied Ergonomics (2006) 